\title{
Los manuales de ELE y su proceso creativo: reflexiones
}

\section{de un autor}

\section{ELE textbooks and their creatives process: an author's reflection}

\author{
Paula Cerdeira núñez \\ COORDINADORA ACADÉMICA DE EXPANISH \\ (CENTRO de ESPAÑol COMO LENGUA EXTRANJERA EN BARCELONA) \\ paula@expanish.com
}

\begin{abstract}
Resumen
Es una realidad que en la mayoría de los centros educativos como universidades, escuelas de idiomas o academias de enseñanza de español como lengua extranjera se utilizan manuales que guían a profesores y aprendientes en su proceso de enseñanza y aprendizaje. Los profesores son conocedores de los manuales existentes en el mercado, conocen su enfoque y metodología y los adaptan a las necesidades de sus clases. Sin embargo, poco saben de su origen y proceso creativo. El objetivo de este artículo es recorrer el camino de elaboración de un manual, desde su nacimiento hasta su publicación.
\end{abstract}

Palabras clave: manuales de ELE, materiales, proceso creativo, autor

\begin{abstract}
It is a real fact that most of the education institutions such as universities, language schools or Spanish teaching academies as a foreign language are using textbooks for guiding teachers and learners in their pedagogic and learning process. The teachers are knowledgeable of all the teaching textbooks in the market. They know the standpoint, methodology and they adjust them accordingly to their needs in class. Nevertheless, they do not always know the background of these teaching textbooks or either their creative process. The main point of this article is going through the making of a teaching handbook from scratch until its publication.
\end{abstract}

Keywords: ELE textbook, materials, creative process, author 


\section{Introducción}

Dentro del proceso de enseñanza de una lengua extranjera los manuales son una herramienta necesaria y valorada por los profesores. En mayor o menor medida se suele coincidir en que un buen manual de enseñanza proporciona muchos beneficios tanto para docentes como para aprendientes: unifica la acción docente presentando una programación para las clases en la que se ofrecen no sólo los objetivos sino también los contenidos y ayuda al alumno y al profesor a organizar la enseñanza/aprendizaje. La conveniencia de un manual no implica necesariamente un uso exclusivo del mismo por parte del profesor, sino que radica en el hecho de que sepa explotarlo de manera eficaz para sus alumnos. El proceso de gestación y elaboración de los manuales es desconocido para muchos profesores $y$, sin embargo, de gran relevancia para su comprensión. Un buen conocimiento de dicho proceso ayudará a los docentes a explorar sus posibilidades y limitaciones, y a tomar decisiones como adaptar algunas actividades a las necesidades del aula o crear material propio.

En este artículo se pretende explorar el proceso de elaboración de un manual desde su inicio a su final, es decir, desde cuando se gesta la idea en la editorial hasta su publicación ${ }^{1}$, prestando especial atención a la labor del autor.

\section{Definición de las etapas del proceso creativo}

Antes de intentar definir las etapas del proceso de creación de los manuales de español como lengua extranjera (ELE, en adelante), se propone reflexionar sobre los conceptos de "proceso" y de "crear" que se definen de la siguiente forma en el DLE (2020):

- Proceso: Conjunto de las fases sucesivas de un fenómeno natural o de una operación artificial.

- Crear: Establecer, fundar, introducir por primera vez algo; hacerlo nacer o darle vida, en sentido figurado.

Estas definiciones nos advierten que este proceso consta de diferentes fases que dan como resultado la aparición de un producto nuevo. Si bien se hace alusión al carácter sucesivo de las fases lo cierto es que, en la gestación de un manual no siempre se dan estrictamente así. En muchas ocasiones, las fases se superponen e, incluso, pueden tener carácter retroactivo.

Con el objetivo de este proceso se propone una división de este en tres fases:

- Definición y descripción del proyecto editorial

\footnotetext{
${ }^{1}$ La exploración y las reflexiones sobre este proceso están basadas en mi propia experiencia como coautora de diferentes manuales de ELE. Es importante aclarar, por lo tanto, que existen otras formas de abordar esta labor.
} 
- Proceso creativo del autor

- Edición y maquetación

\section{Definición y descripción del proyecto editorial}

Este artículo parte de la base de que, normalmente, el germen de un proceso editorial nace en la propia editorial. Sin embargo, es de justicia aclarar que no siempre es así, pues en ocasiones ocurrir que la idea del manual proceda de un autor y sea éste el que lleve la propuesta a la editorial. Pero, independientemente de quién haya tomado la iniciativa, debe existir un proyecto editorial entendido como el documento en el que se justifica la creación de un nuevo producto, es decir, en el que se describa el plan de edición de una obra. En la línea del argumento de Muñoz Pérez (2014), el plan de edición debe justificar el interés del proyecto apoyándose en necesidades como diversas, como la de cubrir nuevos mercados, la de adaptarse a las innovaciones en la metodología y la didáctica de las lenguas extranjeras o la de ajustar la oferta a necesidades emergentes como la incorporación de nuevas tecnologías en la enseñanza.

Los criterios metodológicos y didácticos en los que se basará el manual están recogidos en el Marco Común Europeo de Referencia para las Lenguas (Consejo de Europa, 2002; MCER, en adelante). El Marco común europeo de referencia (MCER) proporciona una base común para la elaboración de programas de lenguas, orientaciones curriculares, exámenes, manuales, etc., en toda Europa. Describe de forma integradora lo que tienen que aprender los estudiantes de lenguas extranjeras con el fin de utilizar una lengua para comunicarse, así como los conocimientos y destrezas que tienen que desarrollar para poder actuar de manera eficaz en la interacción. EI MCER proporciona a los administradores educativos, a los diseñadores de cursos, a los profesores, a los formadores de profesores, a las entidades examinadoras, etc., los medios adecuados para que reflexionen sobre su propia práctica y asegurar que su trabajo satisfaga las necesidades de sus alumnos. (MCER, 2002: 1).

Asimismo, el Plan curricular del Instituto Cervantes (Instituto Cervantes, 2006; PCIC, en adelante) aporta directrices metodológicas y didácticas propias de cada nivel puesto que adapta los objetivos del MCER al aprendizaje del español. Así, el objetivo de las descripciones es especificar los niveles del MCER -que se han desarrollado con valor general, es decir, independientemente de cualquier lengua concreta - para la lengua española y aporta también información sobre el material específico que es considerado necesario para el desarrollo de las competencias de los alumnos (PCIC, 2006).

El desarrollo del plan de edición suele empezar con la creación de un equipo liderado por una dirección editorial encargado de establecer los criterios que determinarán el perfil del manual:

- Perfil de estudiante al que va dirigido el manual: edad, nacionalidad, situación de aprendizaje etc. 
- Tipo de manual. Se define si forma parte o no de un método constituido por manual del estudiante, cuaderno de ejercicios y libro del profesor, y qué niveles se van a ofrecer.

- Definición del enfoque y de la metodología. Se empieza, de esta forma, a configurar su esqueleto ${ }^{2}$ : contenidos funcionales, gramaticales, tratamiento del léxico, tratamiento de la pronunciación, tipología de textos, contenidos culturales y si se considera necesario introducir actividades que potencien el aprendizaje estratégico. Asimismo, se determina si el manual se va a focalizar en la integración de destrezas, en un método comunicativo, ecléctico etc.

- Es muy habitual que las editoriales persigan la creación de manuales flexibles, que puedan abarcar diferentes perfiles de estudiantes y se adapten de la manera más óptima a las necesidades del mercado. Esto implica la necesidad de poseer un conocimiento de la situación del mercado de la enseñanza de ELE y su demanda y de las realidades de las aulas para poder ofrecer flexibilidad y aportar al mismo tiempo algo novedoso y diferenciador.

Una vez decididas estas cuestiones, determinados estos aspectos, la dirección editorial organiza el equipo de creación que generalmente está compuesto por un coordinador editorial, un coordinador pedagógico y un equipo de autores.

\subsection{Coordinador editorial}

El coordinador editorial o editor es el encargado de transmitir al resto del equipo creativo la información relacionada con la confección del manual. Es el momento de transmitir su estructura, aportar un documento de normas y recomendaciones de carácter ortotipográfico y comunicar el tratamiento que debe hacerse de las fotos. Muchas de estas reglas ortotipográficas suelen formar parte tanto del estilo como del diseño editorial, y pueden variar de una publicación a otra. Así como las normas ortográficas son fijas, las ortotipográficas son abiertas ya que se van adaptando a las diferentes publicaciones y van evolucionando con los medios técnicos. Normalmente el establecimiento de estas recomendaciones suele ser un criterio establecido por el equipo directivo y el coordinador editorial. A continuación, se ejemplifican algunas indicaciones que suele transmitir un coordinador editorial ${ }^{3}$ :

Indicaciones relacionadas con la estructura de un manual:

\footnotetext{
${ }^{2}$ Es necesario insistir en que en este punto del trayecto creativo se determina el armazón del manual y será posterior trabajo del coordinador pedagógico transformarlo en una base estable y completa, tal y como se verá en el apartado 3.1.2.

${ }^{3}$ Estas indicaciones no pertenecen a ningún manual específico, sino que proceden de diversos proyectos en los que ha participado la autora de este trabajo.
} 
- El manual consta de 9 unidades de 18 páginas cada una.

- Dos páginas de presentación de contenidos de la unidad.

- Dos páginas de explotación de conocimientos previos.

- Dos páginas dedicadas a la presentación gramatical.

- Dos páginas de presentación y actividades de léxico.

- Dos páginas dedicadas a un tema cultural.

- Dos páginas de evaluación.

- Dos páginas de explotación de un vídeo.

Normas y recomendaciones de carácter ortotipográfico y de uso y tratamiento de fotos:

- Se debe utilizar la letra Times New Roman 12. Se debe justificar texto a la izquierda solamente, y espaciado 0-0, interlineado sencillo.

- No se deben usar demasiados recursos gráficos: negrita para destacar, cursiva para muestras de lengua y ejemplos.

- Las indicaciones al maquetador deben ir entre corchetes y color rojo.

- Se debe ceñir las actividades y fotos a cada página. Una página original corresponde a una página maquetada.

- Se deben seguir las normas del Diccionario de la lengua española $(D L E)$, el Diccionario panhispánico de dudas y la Fundéu (especialmente para el léxico referido a las nuevas tecnologías).

- El autor debe evitar hacer diseños, pero debe escribir indicaciones a los maquetadores de cómo tiene que maquetarse alguna actividad, explicación, texto etc. Por ejemplo: Este texto debe tener el formato de un blog.

- Todas las actividades deben llevar una indicación de dinámica explicando si está diseñada para realizar en parejas o en grupos. Si la actividad se realiza de manera individual no se pone nada.

- La numeración de las actividades solo tiene una subcategoría: 1., 1.1., 1.2. etc.

- En el lenguaje instructivo se usa la persona tú independientemente si la actividad es en grupo o en parejas.

- A la hora de escoger fotos se debe tener en cuenta que las fotos transmiten información, creencias y modo de comportamiento. Se debe evitar fotos insinuantes pues en ciertos mercados las vetan. Hay que copiar la foto a tamaño normal, viendo lo que puede ocupar para ser aproximados con el espacio.

\subsection{Coordinador pedagógico}

Estrechamente ligado al coordinador editorial o editor está la figura del coordinador pedagógico. Su principal labor es concretar y perfilar el proyecto definido previamente por la editorial en líneas más generales y 
proponer un syllabus o programa detallado que se define de la siguiente manera:

Programa es un término equivalente a sílabo (syllabus en el Reino Unido y curriculum en Estados Unidos). Consiste en un plan de trabajo para un curso concreto: descripción de los objetivos, selección y secuenciación de los contenidos y de las actividades, especificación de la metodología y forma de evaluación. Traslada la filosofía del currículo a un plan detallado de enseñanza que variará en función de las características de los aprendientes y de la situación de enseñanza-aprendizaje (Centro Virtual Cervantes, 2008a).

Asimismo, se señala que

Un buen programa proporciona una orientación para el trabajo de profesores y alumnos, ofreciendo un conjunto ordenado de conocimientos y destrezas sobre los que trabajarán y sentando las bases sobre las cuales se podrá evaluar el progreso de los alumnos (Cervantes virtual, 2008a).

Esta definición avala la relevancia que adquiere la confección de un syllabus en el posterior trabajo del autor. Su función es presentar los contenidos que se tratan por unidad: recursos o contenidos comunicativos, lingüísticos, léxicos, culturales etc. siguiendo la estructura marcada previamente por la editorial. Esto implica un análisis previo de diferentes herramientas y obras de consulta como son los anteriormente mencionados MCER y PCIC, además de diferentes artículos y manuales de didáctica. El coordinador pedagógico, para poder ofrecer un programa innovador, debe conocer en profundidad los manuales publicados hasta el momento y tener capacidad de análisis para discernir sus puntos fuertes y sus limitaciones. Es una realidad que no se encuentra en un trabajo de novedad absoluta ya que hay contenidos que deben tratarse indiscutiblemente en un determinado nivel. Si se siguen las directrices del PCIC en un nivel A1 deben presentarse, por ejemplo, contenidos gramaticales como los pronombres sujetos o el presente de indicativo de los verbos ser y estar. Es obvio que la novedad no radicaría en tratar estos contenidos si no en el planteamiento que se haga de su presentación y su posterior explotación. Se parte de la base de que un nuevo manual es una oportunidad para avanzar, ofrecer otras propuestas y no caer en las carencias persistentes en otros manuales y a las que tantos docentes aluden. A lo largo del proceso creativo y según avanza el trabajo de los autores, el syllabus se somete a continuas revisiones debido a las nuevas necesidades que surgen y que derivan en la introducción de cambios y mejoras.

El coordinador pedagógico se encarga también de confeccionar una unidad modelo. Esta unidad normalmente no forma parte del manual publicado, y su objetivo es reflejar el alma del mismo sirviendo de referencia a los autores en su trabajo posterior.

Muñoz Pérez (2014) defiende que tanto el syllabus como la unidad modelo han de ser portadores de un buen grado de novedad dentro de un 
margen de estabilidad y consenso. Estas novedades no se refieren tanto a los contenidos sino a la presentación que se haga de los mismos, a su secuenciación y a los componentes con los que se relacionan y a otros factores como la tipología de las actividades que se proponen, la presentación de la lengua, la incorporación de contenidos culturales o la integración de diferentes destrezas y estrategias.

\subsection{Equipo de autores}

El equipo de autores de un manual de ELE es seleccionado, habitualmente, por la dirección de la editorial. Dicho equipo, como se ha explicado, recibe las indicaciones relacionadas con la estructura y las normas de edición por parte del coordinador editorial o editor, y la información referente al syllabus, a la unidad modelo y a la metodología por parte del coordinador pedagógico. Un método se define como:

Un conjunto de procedimientos, establecidos a partir de un enfoque, para determinar el programa de enseñanza, sus objetivos, sus contenidos, las técnicas de trabajo, los tipos de actividades, y los respectivos papeles y funciones de profesores, alumnos y materiales didácticos.

J. C. Richards y T. S. Rodgers (1998) proponen un modelo para la descripción de los distintos métodos, que se articula en torno a tres ejes: el enfoque, el diseño y los procedimientos. El enfoque permite establecer la base teórica en la que se fundamenta el método: teorías sobre la lengua y sobre el aprendizaje. En el nivel de diseño se determinan los objetivos generales y los específicos, la selección y organización de las actividades de aprendizaje y de enseñanza, y los respectivos papeles de alumnos, profesores y materiales didácticos. En el nivel de los procedimientos se incluyen las técnicas concretas, las prácticas y los comportamientos de profesores y alumnos (Cervantes Virtual, 2008a).

Las decisiones tomadas previamente por el equipo creativo referentes a la definición global del método deben ser trasladadas de manera concisa a los autores para que comiencen a crear siendo coherentes con el método establecido.

Es relevante mencionar que la distribución de este trabajo puede llevarse a cabo de diferentes formas, sin embargo, todas deben partir de la base de que se trata de una labor en equipo con unos miembros coordinados y trabajando en la misma dirección. Es habitual que sea el coordinador pedagógico el que tome estas decisiones y otorgue a cada autor una responsabilidad, siendo conocedor de su equipo y de las debilidades y fortalezas de cada uno de ellos. Entre las diferentes posibilidades de reparto cabe destacar las siguientes:

- Distribución por unidades

- Distribución por secciones o epígrafes

- Distribución por contenidos 
Cada una de ellas presenta ventajas e inconvenientes. Habitualmente, urge publicar el manual y esto implica que los plazos de entrega suelen ser cortos y todo el equipo debe trabajar contra reloj. Si un manual consta de doce unidades y hay tres autores que se encargan de elaborar cuatro unidades de manera simultánea, parece obvio pensar que el proceso creativo se pueda reducir notablemente y como consecuencia, se llegue antes a la publicación. Sin embargo, para conseguir un buen resultado, el coordinador pedagógico debe estar muy atento a que los autores trabajen de manera coordinada, a que todas las unidades tengan una base homogénea y armónica, a que no se repitan temas, y a que los tipos de actividades y textos respeten el método establecido y sean variados y motivadores. Por el contrario, una distribución por epígrafes o por determinados contenidos puede parecer un proceso más lento que ralentizaría aparentemente la fecha de publicación. En cambio, en este caso, todos los autores participan en el proceso de creación fomentando el trabajo cooperativo entre ellos. Esto implica que todas las unidades tengan un corte más homogéneo desde el primer momento y disminuiría la carga de trabajo del coordinador pedagógico.

Independientemente de la distribución que se realice, lo importante es que cada unidad tenga coherencia y cohesión tanto internamente como con el resto del manual.

\section{Proceso creativo del autor}

A lo largo de todos estos años dedicados a la enseñanza de ELE han sido muchas las veces que me he preguntado por los conocimientos que debería tener un profesional que se dedique a la creación de manuales. Siempre he sentido mucha curiosidad por saber cómo se crea un libro y qué papel desempeña el autor dentro del proceso creativo. Ahora, después de participar en diversos proyectos de creación editorial, no son pocos los profesores que me preguntan lo mismo que me planteaba yo hace algunos años. Una de las preguntas más recurrentes es saber hasta dónde llega la creatividad de un autor y si realmente se podría hablar de una creatividad libre o absoluta.

De las definiciones contempladas para la palabra autor, la que se podría acercar más al concepto de un autor de un manual de ELE es la referida al autor como la persona que inventa algo (DLE, 2020). Además, una persona que está inventando está, al mismo tiempo. creando por lo que se entiende que es poseedora de una capacidad creativa. Iglesias Casal (1999: 942) señala que la capacidad creativa supone proyectar sobre las cosas una mirada singular, tiene algo de transgresión y mucho de libertad y existe en cada uno de nosotros. Se trata de una actividad compleja porque a medida que creamos, vamos formando, simplificando, configurando e inventando la realidad. Está estrechamente ligada a la experimentación y significa explorar nuevas direcciones y cambiar las cosas.

Con respecto a los conocimientos que debería tener un autor de manuales debe decirse que, ante todo, un autor suele ser un profesor con 
experiencia que ha trabajado con diversos manuales. Ello le permite caracterizarlos, analizarlos, seleccionarlos y ser consciente de su utilidad ya que estos aspectos son clave en la actividad de los profesores de lenguas extranjeras. Ezeiza Ramos (2009: 4) hace hincapié en la necesidad de que los docentes posean herramientas $\mathrm{y}$ estudios que ayuden a detectar $\mathrm{y}$ comprender qué ofrecen los materiales de enseñanza, cuáles son sus potenciales virtudes y dónde radican sus posibles limitaciones. Tal y como argumenta Muñoz Pérez (2014: 172), cada profesor tiene asimiladas unas ciertas prácticas y habilidades docentes y recurre a su saber hacer a la hora de seleccionar textos, de elaborar secuencias y actividades, o de proponer una determinada visión sobre la lengua. A la experiencia docente se le une, por lo tanto, la experiencia de observación, de puesta en práctica y de adaptación de los manuales y sus actividades a su realidad en el aula. Es necesario apuntar que muchas veces el profesor no trabaja con ningún manual específico y lo crea él mismo, es decir, los autores de manuales cuentan, en muchos casos, con material elaborado previamente para algunas de sus clases y esta labor se refleja en su proceso creativo. Este hecho, además, ofrece la garantía de que este tipo de material ha sido probado en el aula y es posible introducir mejoras en él para integrarlo en el syllabus, o modificarlo y probablemente modernizarlo de manera que se adapte a las características del manual que se está preparando.

Sería una equivocación pensar que el autor parte del vacío absoluto y que crea absolutamente todo el contenido del manual. Con frecuencia, se introducen en él materiales auténticos. Andrijević (2010: 1) señala que una de las principales características de la enseñanza comunicativa es precisamente el uso de materiales auténticos. Melone (2000: 233) alude a dos tipos de materiales didácticos:

- Los materiales creados con fines didácticos: el libro de texto, las cintas o los CD con los diálogos, los vídeos que acompañan al libro, etc.

- Los materiales auténticos, sin un propósito pedagógico, que existen en la realidad y se adaptan: textos de periódicos o revistas, cuentos, novelas, grabaciones de radio, música, folletos, vídeos, etc.

Los materiales auténticos forman parte de la vida cotidiana de todos los hablantes y, como argumenta Andrijević (2010: 2), son textos, imágenes fijas o animadas, grabaciones de voces, textos publicitarios, artículos de prensa, textos literarios, canciones, recetas de cocina, folletos, manuales de instrucciones, calendarios, horarios, etc... Los autores incorporan estos documentos al manual y diseñan actividades para explotarlos didácticamente en función de las dinámicas y de las estrategias de la obra. En ocasiones, aparece también la necesidad de introducir modificaciones en los materiales auténticos para adaptarlos. Según Berardo (2006: 61), las dificultades de los textos auténticos se pueden superar simplificándolos en los niveles lingüísticos (eliminación de las palabras o estructuras gramaticales que no se corresponden con el nivel del manual), cognitivo 
(según la edad, la educación y los intereses del alumno) y psicológico. Estas adaptaciones pueden disminuir el grado de autenticidad de los materiales $y$, por tanto, esta labor debe realizarse de forma muy cuidadosa sin perder nunca de vista el objetivo que se persigue en la selección de los materiales auténtico pensando especialmente en las actividades que se van a diseñar para explotarlos. El tipo de actividad que se proponga posee gran relevancia, ya que debe estar en consonancia con los contenidos del syllabus y el nivel al que va dirigido el manual.

Estrechamente ligado al concepto de creatividad está el concepto de inspiración. Una de las preguntas más frecuentes dirigidas a aquellos profesionales que desempeñan un trabajo creativo es saber cómo se inspira y dónde encuentra esa inspiración. Muchas veces escuchamos a escritores decir que una vivencia o un hecho que les ha sucedido ha sido el motor de su escritura. En el caso de los autores de manuales de ELE, las vivencias están relacionadas con su experiencia docente, con aquellos momentos en que se modificó alguna actividad o se dio un giro a una presentación de contenidos relacionándolo con un tema diferente al que proponía el manual. Esta experiencia docente incluye al aprendiente, protagonista y destinatario del manual. El aprendiente se define como la persona que se encuentra en proceso de aprendizaje de una lengua extranjera y se caracteriza por su triple dimensión: agente social, hablante intercultural y aprendiente autónomo. (Cervantes virtual, 2008a).

La dimensión de agente social explica que las personas aprenden y dan sentido al mundo que las rodea a través de las interacciones en las que participan desde el momento en el que nacen. El aula ELE es un foco de comunicación en el que el aprendiente interactúa con el resto del grupo, por lo que una buena observación por parte del profesor puede aportar mucha información a la hora de confeccionar actividades de interacción en el aula.

La dimensión de hablante intercultural hace alusión al concepto de comunicación intercultural que es la que resulta de la interacción entre hablantes de lenguas y culturas distintas. En ocasiones el aula se transforma en un mapa de diferentes países en el que cada aprendiente representa una manera de ver el mundo según su cultura y tradiciones. Las actividades que fomentan la competencia intercultural son una fuente de conocimiento directo de pautas culturales que se convierten en la base para plantear nuevas actividades.

La dimensión del aprendiente autónomo se refiere a la capacidad que desarrolla el alumno para organizar su propio proceso de aprendizaje. Tal y como indica el Diccionario de términos en clave de ELE (Cervantes Virtual, 2008a), la autonomía en el aprendizaje es intencional, consciente, explícita y analítica. El aprendiente desempeña, por lo tanto, un papel muy relevante en su proceso de aprendizaje por lo que es necesario fomentar en el aula tareas en las que puedan intercambiar estrategias y estilos de aprendizaje. Una observación atenta de estas estrategias por parte del profesor da como resultado nuevas aportaciones para el diseño de actividades que favorezcan el aprendizaje autónomo. 
Tal y como hemos apuntado anteriormente muchos escritores consideran que sus propias experiencias están en el origen de su inspiración, pero también son muchos los que defienden la idea de que no necesariamente se tiene que escribir sobre experiencias vividas o referidas. La base para escribir sobre algo que no se haya vivido está en la documentación, en instruirse e informarse sobre aquello de lo que se quiere escribir. Los autores de manuales de ELE encuentran esta documentación en las obras de referencias especializadas como son los anteriormente citados MCER y PCIC, las gramáticas, los libros de didáctica, otros manuales de enseñanza, los diccionarios, los libros de estilo, las revistas especializadas y la participación en cursos, congresos y encuentros dedicados a la enseñanza y al aprendizaje de ELE. En Las competencias clave del profesorado de lenguas segundas y extranjeras (Instituto Cervantes, 2012) se hace alusión a la necesidad del profesor de ELE y, por lo tanto, también a la necesidad de un autor de manuales de ELE de formarse profesionalmente. Se trata de una competencia y se refiere a la capacidad del profesorado para planificar, gestionar y evaluar su propio proceso continuo de formación, con el fin de responsabilizarse de su desempeño profesional. Un autor debe estar en continuo proceso de formación, participando en encuentros de enseñanza donde se comparten ideas, experiencias y se aportan nuevas investigaciones y perspectivas de grandes profesionales del mundo de ELE. No cabe duda de que de aquí pueden surgir planteamientos interesantes de presentaciones de contenidos, actividades y dinámicas que, unidas a la capacidad creativa del autor, pueden materializarse en un nuevo manual.

Por último, es importante también la personalidad de cada uno de los autores que forman el equipo, entendida como las características de cada persona que la distinguen de los demás. (DLE, 2020).

Cada autor puede aportar su granito de arena personal haciendo uso de sus capacidades creativas y de sus conocimientos e intereses, seleccionando aquellos que puedan incluirse en el manual y plasmándolos de una manera creativa: conocimientos de historia, de psicología, de música, de pintura, de literatura, cine etc.

\section{Edición y maquetación}

Es habitual que cuando los autores terminan las unidades se las entreguen al coordinador pedagógico para que pueda revisarlas, hacer las correcciones didácticas pertinentes y sugerir cambios si es preciso ${ }^{4}$. Una vez se realicen estos cambios y el coordinador pedagógico dé su conformidad, se envían estas unidades al coordinador editorial y es a partir de aquí cuando tal y como señala Muñoz Pérez (2014) se abre un proceso de retroalimentación con el equipo editorial en el que el editor va a revisar aspectos técnicos

\footnotetext{
${ }^{4}$ Es conveniente poner en práctica en el aula este material antes de entregarlo. Si es posible el autor lo puede comprobar en sus propias clases o pedir a otros profesores que lo lleven a sus clases con el objetivo de hacer una observación crítica del mismo: ver cómo responden los alumnos y sugerir cambios en caso necesario.
} 
relacionados con la distribución en el espacio, ilustraciones, paginación, analizar si los componentes del método están bien articulados y revisar si se ha tratado algún tema tabú en una determinada cultura ${ }^{5}$. Como consecuencia de estas revisiones, se rectifican secuencias, se adaptan textos, instrucciones y explicaciones etc.

Muchas veces la visión de un coordinador editorial o editor y un autor suele partir de bases diferentes ya que el primero debe adaptar la creación del autor a las necesidades de maquetación y paginación y el autor es un profesor que suele priorizar los aspectos más didácticos centrándose en crear el material visualizando cómo llevarlo al aula. Uno de los ejemplos más habituales es la concepción del espacio dedicado a las actividades porque, aunque previamente se dan directrices al respecto, el producto no suele coincidir con las posibilidades reales. Es común que el editor ya vea claramente antes de pasar la unidad al departamento de maquetación que será necesario adecuar algunas actividades. En algunos casos es el editor con el soporte del coordinador pedagógico el que toma la decisión de hacer algún cambio inmediato: eliminar alguna actividad breve o adaptarla de manera que se pueda incorporar en la actividad anterior o cambiar la actividad de comprensión lectora y convertirla en comprensión auditiva, ya que la transformación de un texto en una audición repercute en espacio ganado. Sin embargo, cuando el editor ve que los cambios pueden poner en peligro la secuenciación y la coherencia y cohesión de la unidad, ésta vuelve a manos de los autores para que la reestructuren.

Se revisan también todas aquellas anotaciones que los autores dirigen a los maquetistas relacionadas con el diseño de las actividades o textos (tablas, etiquetas, cuadros etc.), así como las posibles ilustraciones e imágenes que se proponen. Normalmente la editorial cuenta con un banco de imágenes que pone a disposición de los autores para que las seleccionen. Puede suceder que la fotografía que se necesite tenga derechos de autor y no esté en el banco de imágenes por lo que la editorial valorará la viabilidad de ponerse en contacto con el propietario para pedir las licencias pertinentes $^{6}$. En el caso de que se puedan hacer ilustraciones, el editor revisará las anotaciones dadas por el autor y se asegurará que estén claras para que el ilustrador pueda hacer su trabajo.

Cuando esta fase de retroalimentación entre coordinadores y autores finaliza, la unidad está preparada para maquetar y es cuando entran en juego los maquetadores, ilustradores y diseñadores gráficos. Ellos son los responsables de darle forma a la unidad siguiendo las directrices de autores y coordinadores. Una vez terminada la primera maqueta es habitual enviar la unidad a los coordinadores para que puedan revisar y comprobar que todo esté en orden: que la numeración de las actividades y audios sea correcta,

\footnotetext{
${ }^{5}$ Es frecuente que las editoriales tengan como objetivo que el manual se venda en el mayor número de países, por lo que hay que ser muy cuidadoso con la elección de temas y analizar previamente si en determinadas culturas son considerados conflictivos o tabú.

${ }^{6}$ Lo mismo sucede con los textos escritos o audios. En muchos casos los audios son creados o adaptados por el propio autor, pero en el caso de que requiera de la cesión de derechos de autor, será la editorial la encargada de realizar la gestión.
} 
que las instrucciones no estén cortadas o que las presentaciones y explicaciones gramaticales se vean claras. También puede suceder que no se haya calculado bien el espacio y quede algún hueco por rellenar y sean los autores los que deban completarlo añadiendo alguna actividad. Se procede, de nuevo a revisiones exhaustivas y cuando ya se contempla la versión definitiva se pasa a un corrector que será el encargado de depurar, revisando los errores ortotipográficos y verificando que exista una unificación en el estilo y en las explicaciones. Después se procede a las últimas modificaciones por parte del editor, se envía la maqueta a imprenta y se trabaja en las grabaciones de las audiciones. Una vez impresos los manuales se procede a su publicación llegando al final de este proceso creativo.

\section{Conclusión}

Como ha podido verse, el proceso de creación de un manual es una labor en equipo que forma parte de un engranaje en el que todas las piezas deben trabajar de manera armónica y coordinada, respetando tanto los roles asignados como las pautas establecidas. Todas son importantes e imprescindibles y si una se descoordina, ello repercutirá negativamente en el trabajo de la pieza posterior.

El autor es, por lo tanto, una parte fundamental en este trayecto creativo. Su trabajo está delimitado por una serie de directrices a seguir que, si se respetan, no son incompatibles con los conceptos de libertad creativa y de innovación. Se aboga por un autor con experiencia en la enseñanza, conocedor de los distintos manuales de ELE, y que en su haber docente haya adaptado y creado actividades para sus estudiantes. Su inspiración procede de dos fuentes: su experiencia en el aula y su experiencia vital, unida a su personalidad, a sus gustos y sus conocimientos en otras áreas.

Finalmente queremos animar a profesores, autores y equipos editoriales a seguir trabajando e innovando en la creación de nuevos manuales que faciliten la grata labor relacionada con la enseñanza y el aprendizaje del ELE.

\section{BiBLIOGRAFÍA}

ANDRIJEVIĆ, Maja (2010): "Reflexiones en torno al uso de los materiales auténticos en la enseñanza de lenguas extranjeras", Colindancias, 1. https://colindancias.uvt.ro/index.php/colindancias/article/view/113 $\angle 95$

Berardo, Sacha A. (2006): "The use of authentic materials in the teaching of reading", The Reading Matrix, Vol. 6, № 2.

Centro Virtual Cervantes (2008a): Diccionario de términos clave de E/LE. https://cvc.cervantes.es/Ensenanza/biblioteca ele/diccio ele/defa ult.htm

Centro ViRtual Cervantes (2008b): "Las competencias claves del profesorado de lenguas segundas y extranjeras". 
https://cvc.cervantes.es/ensenanza/biblioteca ele/competencias/d efault.htm

InStituto CeRVANTES (2006): Plan curricular del Instituto Cervantes. Niveles de referencia para el español. Madrid: Biblioteca nueva.

Consejo de EUROPA (2002): Marco común europeo de referencia para las lenguas: aprendizaje, enseñanza, evaluación. Madrid: Ministerio de Educación, Cultura y Deporte.

DLE = REAL ACADEMIA ESPAÑola (2020): Diccionario de la lengua española . Versión en línea. https://www.rae.es/

EzeIzA RAmos, Joseba (2009): “Analizar y comprender los materiales de enseñanza en perspectiva profesional: Algunas claves para la formación del profesorado", Marcoele, 9. https://marcoele.com/descargas/9/ezeiza1.pdf

Gelabert, María José; Bueso, Isabel y Benítez, Pedro (2002): Producción de materiales para la enseñanza de español Madrid: Arco/Libros.

IGLESIAS CASAL, Isabel (1999): "La creatividad en el proceso de enseñanzaaprendizaje de ELE: Caracterización y aplicaciones”, Centro Virtual Cervantes, Publicaciones de la Asele. https://cvc.cervantes.es/ensenanza/biblioteca ele/asele/pdf/10/10 0937.pdf

Melone, Enrique L. (2002): “Cómo trabajar con textos. Análisis de materiales didácticos", Actas del VIII Seminario de Dificultades Específicas de la Enseñanza del Español a Lusohablantes. São Paulo.

MUÑOZ PÉREZ, Julián (2014): "El proceso de elaboración de manuales de ELE", redELE, número especial, pp. 166-180.

https://www.researchgate.net/publication/338019921 El proceso de elaboracion de manuales de ELE

RICHARDS, Jack y RODGERS, Theodore (1986): Enfoques y métodos en la enseñanza de idiomas. Madrid: Cambridge University Press. 